\title{
Finite element analysis of Cymbal piezoelectric transducers for harvesting energy from asphalt pavement
}

\author{
Hongduo ZHAO, ${ }^{\dagger}$ Jian YU* and Jianming LING \\ Key Laboratory of Road and Traffic Engineering of Ministry of Education, Tongji University, Shanghai 201804, China \\ ${ }^{*}$ Functional Materials Research Laboratory, Tongji University, Shanghai 200092, China
}

The purpose of this paper is to design a Cymbal for harvesting energy from asphalt pavement. Asphalt pavement is used popular on road. Part of the energies in the pavement caused by vehicle and gravity can be harvested by piezoelectric transducers. Cymbal is selected to harvest energy from asphalt pavement because of its low cost, high reliability and reasonable efficiency. The efficiency and coupling effects with pavement of Cymbals with various sizes are discussed through finite element analysis (FEA). The displacement difference at pavement surface between with and without Cymbal is developed to considering the coupling effects. The results show that the potential electric energy harvested from pavement increases with the diameter of Cymbal. However, the efficiency decreases with the increasing of Cymbal size. The diameter at $32 \mathrm{~mm}$ is suggested as the size of Cymbal. The potential electric energy increases near linearly with the diameter of end cap cavity base. Enough bonding area should be left to bond the end steel cap and PZT. There is a maximum electric energy existing when the top diameter of the end steel cap changes. The maximum electric energy is generated when the thickness of cap steel is about $0.3 \mathrm{~mm}$. There is also a maximum electric energy existing when the height of end cap cavity changes. The Cymbals with thicker PZT can generate higher electric potential and storage electric energy. Considering the storage electric energy, cost, bonding between end steel cap and PZT and the pavement surface displacement, the Cymbal with $32 \mathrm{~mm}$ of total diameter, $22 \mathrm{~mm}$ of cavity base diameter, $10 \mathrm{~mm}$ of end cap top diameter, $0.3 \mathrm{~mm}$ of cap steel thickness, $2 \mathrm{~mm}$ of cavity height and $2 \mathrm{~mm}$ of PZT thickness is suggested as the optimum one for harvesting energy from asphalt pavement. The electric potential is about $97.33 \mathrm{~V}$ of the design Cymbal. $0.06 \mathrm{~J}$ electric energy can be storage in that Cymbal. Its potential maximum output power is about $1.2 \mathrm{~mW}$ at $20 \mathrm{~Hz}$ vehicle load frequency.

(-2010 The Ceramic Society of Japan. All rights reserved.

Key-words : Energy harvesting, Piezoelectric, Cymbal, Asphalt pavement, Finite element analysis

[Received June 15, 2010; Accepted August 19, 2010]

\section{Introduction}

Asphalt pavement is one of the pavement structures used widely in roads, runways and parking lots. The mileages of asphalt pavement in China are more than 500,000 km. ${ }^{1)}$ During the lifetime of the asphalt pavements up to millions vehicles will pass on them. The loads of moving vehicle cause stress, strain, deformation and vibration in pavement. At the same time, the pavement obtains strain and kinetic energies from the work of vehicle load and gravity (see Fig. 1). The external work of pavement from one truck with 6 tires is more than $1 \mathrm{~J}$. Those energies are dissipated in the pavement environment as waste thermal energy (part A in Fig. 1), which leads to more risk of pavement rutting. If piezoelectric transducers are embedded in the pavement, part of those energies can be harvested by transforming them into electric energy (part B in Fig. 1).

The mechanical energy in the pavement is mostly caused by the stress of the moving vehicle (stress driven). It can be harvested by converting it into electric alternating current using piezoelectric transducers, such as multilayer, Moonie, Cymbal, THUNDER etc. A successful pavement generator should have high efficiency, coupling well with pavement, long lifetime, and low cost. It is reported that Cymbal has reasonable efficiency, high durability under large load, medium stiffness and low cost. $^{2-4)}$ Cymbal seems a good choice for harvesting energy under high stress environment like asphalt pavement.

\footnotetext{
Corresponding author: H. Zhao; E-mail: hdzhao@tongji.edu.cn
}

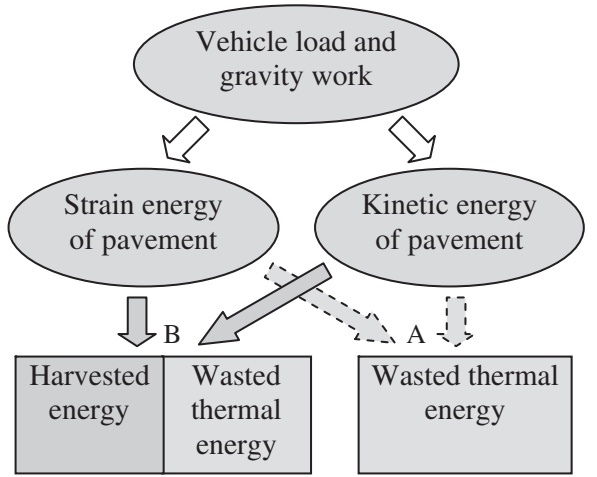

Fig. 1. The energies of pavement.

Cymbal is developed by Pennsylvania State University in $1990 \mathrm{~s},{ }^{3), 5)}$ whose structure is shown in Fig. 2. It is a composite of thin PZT (lead zirconate titanate) disk and metal end cap at both sides of PZT. The PZT is polarized in thickness direction. An electric potential is generated on the electrode surface because of the piezoelectric effects of PZT when the load is applying on the end metal cap in the vertical direction.

This paper is aimed at discussing the performance of Cymbal with various shape parameters for harvesting mechanical energy from asphalt pavement via finite element analysis (FEA). The potential storage electric energy related to the size of Cymbal and stress distribution is presented. At the same time, the coupling effects between Cymbal and pavement are also discussed, which are indicated by the displacements at pavement surface. Past 


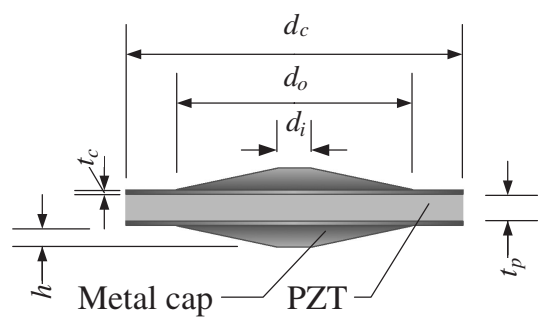

Fig. 2. Shape of Cymbal.

studies were mainly about the performance of Cymbal under the application of an electric field, such as the size, displacement and vibration frequency. ${ }^{3), 6)-10)}$ The energy harvesting performance of a Cymbal with diameter $=29 \mathrm{~mm}$ was studied by Kim et al. ${ }^{11-13)}$ However, no results were reported for harvesting energy from asphalt pavement via Cymbal.

\section{Literature review}

Cymbal is modified from Moonie in order to reduce the stress concentration in metal cap, which is used as a hydrophone. Cymbal has larger displacement, larger generative forces, and lower cost. ${ }^{3)}$ The performance as an underwater projector or receiver had been studied by many researchers since Cymbal was developed. It is reported that the displacement of Cymbal decreases with the increasing of $h .{ }^{9}{ }^{\text {T }}$ The first resonance frequency of Cymbal decreases with increasing of $d_{c}$ or $d_{o}{ }^{6), 7)}$ With the decreasing of the cavity depth $h$, cap thickness $t_{c}$ or PZT thickness $t_{p}$, the first resonance frequency decreases because of decreased device stiffness. ${ }^{6,7), 10)}$ The influence of cap material to the first resonance frequency was discussed by Newnham ${ }^{7)}$ and Wang. ${ }^{8}$ FEA are used in those analysis based on ANSYS or ATILA code. Those relations between size of Cymbal and performance give us some guides to design a Cymbal for harvesting energy from asphalt pavement. However, more factors like output energy and coupling effects with pavement should be considered deeply.

Kim $^{11)-13)}$ tested a Cymbal with $d_{c}=29 \mathrm{~mm}, d_{o}=17 \mathrm{~mm}$, $d_{i}=5 \mathrm{~mm}$ and $h=1 \mathrm{~mm}$; three kinds of PZT: hard, soft and high $g$ were used in the laboratory test. The peak voltage of the high $g$ Cymbal was about $374 \mathrm{~V}$ under a cyclic force of $7.8 \mathrm{~N}$ at $100 \mathrm{~Hz}^{11)}$ There was about $0.2 \mathrm{~J}$ electric energy obtained within $20 \mathrm{~s} .{ }^{11)}$ Furthermore, the output power and output voltage varied with different resistive load were examined. The output power increased with the increasing of force frequency, and there was a maximum output power with the increasing of resistance load. ${ }^{11)-13)}$ Higher output power was obtained at thinner end cap and PZT thickness, and a maximum output power about $42 \mathrm{~mW}$ was measured at the Cymbal with $t_{c}=0.4 \mathrm{~mm}$ (steel) and $t_{p}=1 \mathrm{~mm}$ under a force of $40 \mathrm{~N}$ at $100 \mathrm{~Hz}^{12)}$

Based on the same Cymbal, the stress distribution in PZT of the Cymbal under $70 \mathrm{~N}$ at $100 \mathrm{~Hz}$ was explored via FEA. ${ }^{12)}$ The stress in PZT under the area contacting with the end cap was almost compressive, which was very small. The stress in PZT under the cavity area was almost tensile stress, which was the mainly reason leading PZT to generate piezoelectric effects. In 1997, Dogan ${ }^{3)}$ analyzed the stress in PZT of a Moonie via FEA. The stresses at radial direction under the cavity area were tensile stress; and both compressive and tensile stresses were existed in PZT under the contact area. However, the stress in pavement caused by the moving vehicle is differing from the cyclic force used in the laboratory. The stress distribution in the PZT under pavement environment needs to be explored.

\section{Piezoelectric effects}

PZT will generate electric field under the application of stress, it is called piezoelectric effects; in the reverse, PZT will generate strain under the application of an electric field. The piezoelectric equations are described as Eqs. (1) and (2). ${ }^{14), 15)}$

$$
\begin{aligned}
& \boldsymbol{S}_{i}=\boldsymbol{s}_{i j}^{\boldsymbol{E}} \boldsymbol{T}_{j}+\boldsymbol{d}_{m i} \boldsymbol{E}_{m} \\
& \boldsymbol{D}_{m}=\boldsymbol{d}_{m i} \boldsymbol{T}_{i}+\boldsymbol{\varepsilon}_{m k}^{\boldsymbol{T}} \boldsymbol{E}_{k}
\end{aligned}
$$

Where, $i, j=1,2,3, \ldots, 6 ; m, k=1,2,3 ; \boldsymbol{S}$ is the strain tensor; $\boldsymbol{T}$ is the stress tensor; $\boldsymbol{s}^{\boldsymbol{E}}$ is the compliance tensor of PZT test at constant $\boldsymbol{E}$ condition; $\boldsymbol{E}$ is the external electric fields; $\boldsymbol{D}$ is the charge displacement tensor; $\boldsymbol{d}$ is piezoelectric strain constant tensor; $\boldsymbol{\varepsilon}^{\boldsymbol{T}}$ (permittivity) is dielectric constant tensor measure at constant $\boldsymbol{T}$ condition.

For Cymbal used to harvest energy, only the piezoelectric effects will be considered, i.e., the external electric field $E=0$. Under the vertical force of pavement, a polarization $P_{3}$ appears on the vertical surface (assume as the 3rd axial direction) of PZT. Then Eq. (2) can be rewritten as Eq. (3).

$$
P_{3}=\sum_{i=1}^{6} d_{3 i} T_{i}
$$

Where, $P_{3}$ is the piezoelectric polarization at direction 3, whose magnitude is equal to the charge density at the applied surface.

The polarization of PZT leads to an internal electric field in PZT:

$$
E_{3}=\frac{P_{3}}{\varepsilon_{33}^{T}}
$$

or

$$
E_{3}=\sum_{i=1}^{6} g_{3 i} T_{i}
$$

Where, $E_{3}$ is the internal electric field in PZT; $g_{3 i}$ is the piezoelectric voltage constant of PZT.

Then the relation between $g$ and $d$ can be obtained from Eqs. (3) and (4):

$$
\begin{aligned}
& g_{3 i}=\frac{d_{3 i}}{\varepsilon_{33}^{T}}=\frac{d_{3 i}}{\varepsilon_{33 r}^{T} \varepsilon_{0}} \\
& V_{3}=\int E_{3} d t_{p}=\sum_{i=1}^{6} \int g_{3 i} T_{i} d t_{p}
\end{aligned}
$$

Where, $\varepsilon_{33 r}^{T}$ is the relative dielectric constant of PZT; $\varepsilon_{0}$ is the dielectric constant of vacuum; $V_{3}$ is the electric potential (voltage) at the direction 3 caused by polarization changing, which can be obtained via FEA; $t_{p}$ is the thickness of PZT.

Maximizing the output electric energy is the key to design the Cymbal for harvesting energy. The electric energy stored in the Cymbal can be calculated by Eq. (8).

$$
U_{E}=\frac{1}{2} P_{3} E_{3} A t_{p}=\frac{1}{2} V^{2} \frac{\varepsilon_{r}^{T} \varepsilon_{0} A}{t_{p}}
$$

Where, $U_{E}$ is the stored electric energy; $A$ is the surface area of PZT disk.

\section{Evaluation factors}

A successful pavement generator should have the ability that it can convert as more as possible mechanical energy and maintain the performance of the pavement. It is discussed in this paper via FEA considering the coupling effect of Cymbal and asphalt pavement. The efficiency of a transducer is always evaluated by the electromechanical coupling factor $k$ and the energy trans- 


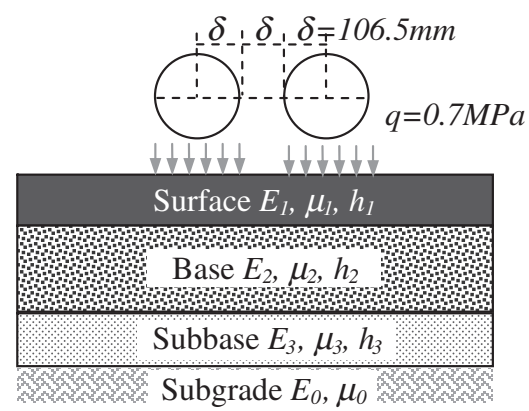

Fig. 3. The loads and structure of pavement.

mission coefficient $\lambda_{\max }$. However, it is difficult to calculate the effective $k$ and $\lambda_{\max }$ in a complicated Cymbal-Pavement coupling system. Instead of them, the storage electric energy at open circuit, which is related to the energy convert efficiency and potential power, is used to evaluate the energy harvesting ability of Cymbal in this paper.

At the same time, the embedded Cymbal should not reduce the performance of the pavement, and increase the fuel consumption of the vehicle. It can be controlled by the displacement on the surface of asphalt pavement. If the surface displacement of the pavement with Cymbal is almost same or even less than the displacement without Cymbal, it indicates that the Cymbal has good coupling with pavement.

Summarizing from above, the storage electric energy at open circuit and surface displacement on the pavement are used as the evaluating factors in this paper.

\section{FEA models and parameters}

ABAQUS is used in this paper to perform the mechanical and piezoelectric analysis, in which piezoelectric equations (1) and (2) are used.

\subsection{Pavement structure and load}

The responses of pavement are various with vehicle loads and pavement structures and materials. In general, the vehicle can be divided into two groups: small cars (with four tires) and large cars (trucks and buses). The typical tire pressure is between $0.2-$ $0.25 \mathrm{MPa}$ for small cars, and between $0.5-1.0 \mathrm{MPa}$ for large cars. The large cars are analyzed in this paper. For most analysis in pavement engineering, the contact pressure between tire and pavement is assumed to equal the tire pressure, and the shape of contact area is assumed to round. Typical asphalt pavement structure and dual tire loads are shown as Fig. 3. Only one tire load is considered in this paper because the size of Cymbal is small comparing to the contact area. Contact stress $q=0.7 \mathrm{MPa}$ $(25 \mathrm{kN}$ for one tire) is accepted in FEA.

The surface of asphalt pavement always includes 2-3 layers, in which the thickness of the top layer is about $40 \mathrm{~mm}$. The Cymbal should be embedded in the pavement as close as possible to the surface to get more energy. However, it is very hard to embed Cymbals in one asphalt pavement layer. Thus, the bottom of the top layer of the pavement is the best location to set the Cymbals, which is about $40 \mathrm{~mm}$ depth. In order to put more attention on the Cymbal, only the surface layers of asphalt pavement are considered in FEA.

\subsection{Material properties}

Elastic material properties are used for asphalt pavement, end cap and PZT. Steel is used to model the end cap and PZT 5H is
Table 1. Pavement and steel material properties

\begin{tabular}{lcc}
\hline Material & $\begin{array}{c}\text { Elastic module } \\
E(\mathrm{MPa})\end{array}$ & $\begin{array}{c}\text { Poisson ratio } \\
\mu\end{array}$ \\
\hline Asphalt concrete & 1,500 & 0.35 \\
Steel & 200,000 & 0.3 \\
\hline
\end{tabular}

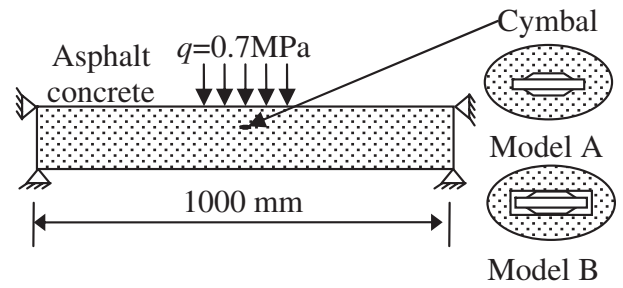

Fig. 4. FEA models.

chosen as the PZT material because of its high $(d \cdot g)$ value. The material properties are listed in Table 1 and Eqs. (9)-(11). ${ }^{14)}$

$$
\begin{aligned}
d_{m i} & =\left(\begin{array}{cccccc}
0 & 0 & 0 & 0 & 741 & 0 \\
0 & 0 & 0 & 741 & 0 & 0 \\
-274 & -274 & 593 & 0 & 0 & 0
\end{array}\right) \mathrm{pC} / \mathrm{N} \\
c_{i j}^{E} & =\left(\begin{array}{cccccc}
126 & 79.5 & 84.1 & 0 & 0 & 0 \\
79.5 & 126 & 84.1 & 0 & 0 & 0 \\
84.1 & 84.1 & 117 & 0 & 0 & 0 \\
0 & 0 & 0 & 23 & 0 & 0 \\
0 & 0 & 0 & 0 & 23 & 0 \\
0 & 0 & 0 & 0 & 0 & 23.3
\end{array}\right) \mathrm{GPa} \\
\varepsilon_{m k r}^{S} & =\left(\begin{array}{ccc}
1700 & 0 & 0 \\
0 & 1700 & 0 \\
0 & 0 & 1470
\end{array}\right)
\end{aligned}
$$

Where, $c_{i j}^{E}$ is the stiffness matrix; $\varepsilon_{m k r}^{S}$ is the relative dielectric constant at constant strain.

\subsection{FE model}

Considering the contacting of asphalt pavement and Cymbal, two types of cylinder models are submitted to FEA (see Fig. 4). The diameter of asphalt is $1 \mathrm{~m}$. Its thickness is $40 \mathrm{~mm}$ above cymbal and $110 \mathrm{~mm}$ under the cymbal. The diameter of the load area is $213 \mathrm{~mm}$. The load, size and material for model A and B are the same. The only different between them is contact between Cymbal and asphalt concrete. Cymbal is surrounded by asphalt concrete directly in model A, and is placed in a metal box in model B. The axial symmetry modeling technique is used in FEA.

\subsection{Comparing of model $\mathrm{A}$ and $\mathrm{B}$}

A Cymbal with $d_{c}=32 \mathrm{~mm}, d_{o}=22 \mathrm{~mm}, d_{i}=10 \mathrm{~mm}$, $h=2 \mathrm{~mm}, t_{c}=0.3 \mathrm{~mm}$, and $t_{p}=2 \mathrm{~mm}$ is modeled to comparing the efficiency of model A and B (thickness of steel box shell is $0.3 \mathrm{~mm}$ ). The electric potential in the Cymbal of model A is shown as Fig. 5. The electric potential is set to zero at the bottom metal cap. The maximum electric potential is $97.33 \mathrm{~V}$ in model $\mathrm{A}$ and $76.53 \mathrm{~V}$ in model B. There is about $0.07 \%$ increasing of the pavement surface displacement at the center point in model $\mathrm{A}$, which is almost same as the normal pavement. Thus, the model $\mathrm{A}$ is chosen to discuss for the following FEA. 


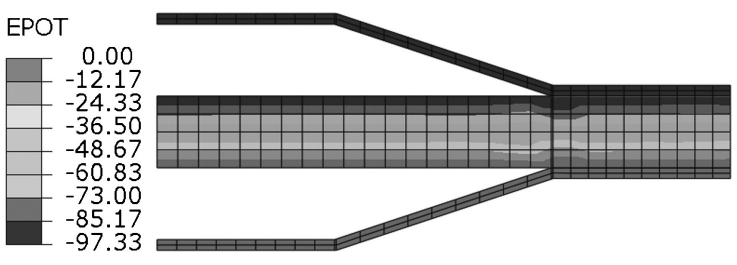

Fig. 5. Electric potential in cymbal of model A.

Table 2. Shape parameters of Cymbals

\begin{tabular}{ccccc}
\hline Size & \multicolumn{4}{c}{ Value $(\mathrm{mm})$} \\
\hline$d_{c}$ & 10 & 20 & 30 & 40 \\
$d_{o}$ & 6 & 12 & 20 & 24 \\
$d_{i}$ & 4 & 8 & 12 & 16 \\
$h$ & 1.0 & 1.0 & 1.0 & 1.0 \\
$t_{c}$ & 0.4 & 0.4 & 0.4 & 0.4 \\
\hline
\end{tabular}

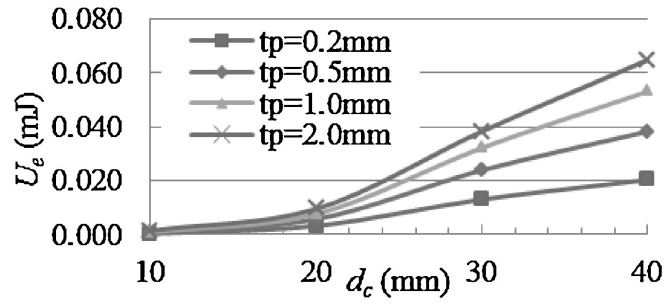

Fig. 6. Potential electric energy with various $d_{c}$.

\section{Selecting the diameter of PZT}

The size of Cymbal will significantly influence the output electric energy. Variant sizes of PZT disk are available in the market. The Cymbals with $d_{c}=10 \mathrm{~mm}, 20 \mathrm{~mm}, 30 \mathrm{~mm}$ and $40 \mathrm{~mm}$ are analyzed. The other shape parameters are listed in Table 2.

\subsection{Potential electrical energy}

The potential electric energy $\left(U_{e}\right)$ stored in transducer can be calculated by Eq. (8), in which the electric potential is obtained by FEA. Figure 6 shows the potential electric energy of the Cymbals with various $d_{c}$. It can be concluded that the potential electric energy increases with $d_{c}$. From that point, larger Cymbal is recommended to get more energy.

\subsection{Coupling with pavement}

Embedded Cymbal should not increase the surface displacement when they work in the pavement. The center displacement at the top of the model is used to examine the coupling effect of Cymbal and pavement. The displacement difference percent with and without cymbal can be calculated by Eq. (12). As shown in Fig. 7, the surface displacement of pavement changes with $d_{c}$. There is a maximum $p_{d}$ near $d_{c}=20 \mathrm{~mm}$. The $p_{d}$ becomes negative between $d_{c}=20-30 \mathrm{~mm}$ for thinner $t_{p}$, which indicates the $d_{w}$ is larger than $d_{w o}$. The pavement surface displacement are all reduced by all size Cymbals because of their high stiffness when $t_{p}=2.0 \mathrm{~mm}$.

$$
p_{d}=\frac{d_{w o}-d_{w}}{d_{w o}} \times 100 \%
$$

Where $p_{d}$ is the displacement difference percent; $d_{w o}$ is the displacement without Cymbal; $d_{w}$ is the displacement with Cymbal.

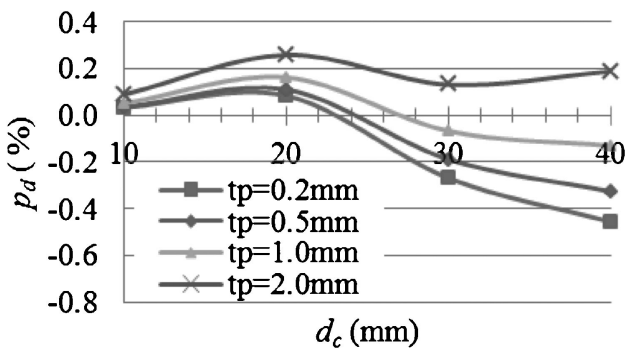

Fig. 7. Displacement difference of model A.

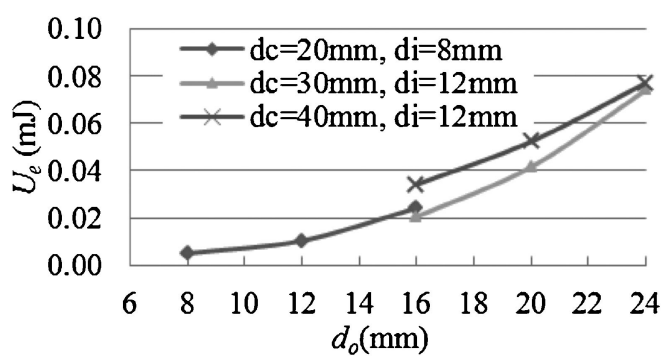

Fig. 8. $U_{e}$ vary in $d_{o}$

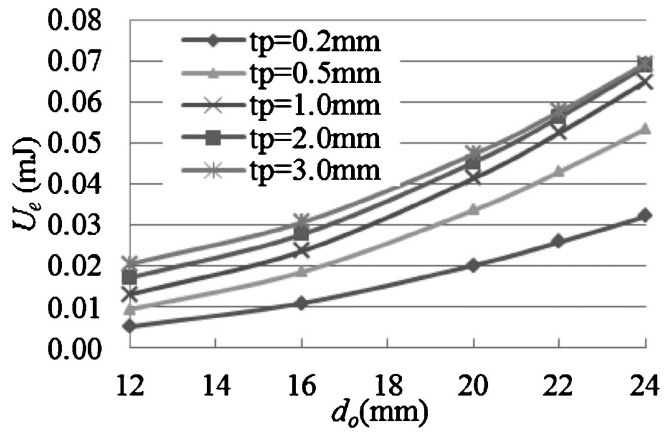

Fig. 9. $U_{e}$ vary in $d_{o}$

Considering the cost of PZT disk, potential electrical energy and coupling with the pavement, the diameter of Cymbal had better near $30 \mathrm{~mm}$. In order to give the Cymbal a uniform contact, the size of Cymbal had better be 2-3 times of the large size of the aggregate in asphalt pavement, which is $13-16 \mathrm{~mm}$. Thus, a diameter at $32 \mathrm{~mm}$ is decided as the optimum size of Cymbal.

\section{Defining other size parameters}

In addition to the diameter of Cymbal, other size parameters also influence the potential electric energy, such as $d_{o}, d_{i}, h, t_{c}$, and $t_{p}$.

\subsection{Effects of $d_{0}$}

The effects of $d_{o}$ with various $d_{c}$ are examined by FEA $\left(h=1 \mathrm{~mm}\right.$ and $\left.t_{c}=0.4 \mathrm{~mm}\right)$. As shown in Fig. 8, the $U_{e}$ increases near linearly with $d_{o}$ for all $d_{c}$. More details are explored for the Cymbal with $d_{c}=32 \mathrm{~mm}, h=2.0 \mathrm{~mm}$, $t_{c}=0.3 \mathrm{~mm}$, and $d_{i}=8 \mathrm{~mm}$. The results are shown in Fig. 9 . Those curves in Fig. 9 show that the $U_{e}$ increases with $d_{o}$. However, the surface displacement of pavement also increases with $d_{o}$ as shown in Fig. 10. The surface displacement with Cymbal begins larger than the value without Cymbal $\left(p_{d}<0\right)$ near $d_{o}=22 \mathrm{~mm}$ for $t_{p}=2.0 \mathrm{~mm}$. It indicates that $d_{o}$ had better no larger than $22 \mathrm{~mm}$ for $t_{p}=2.0 \mathrm{~mm}$. 


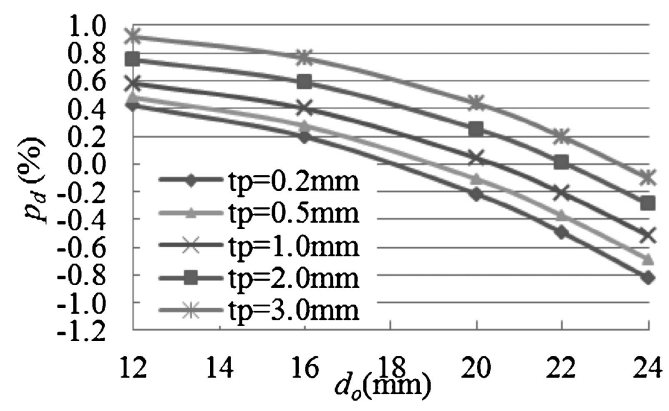

Fig. 10. Relation between $p_{d}$ and $d_{o}$.

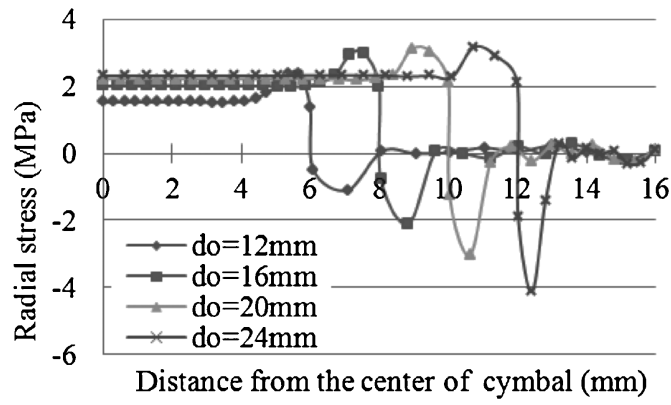

(a) Top of PZT

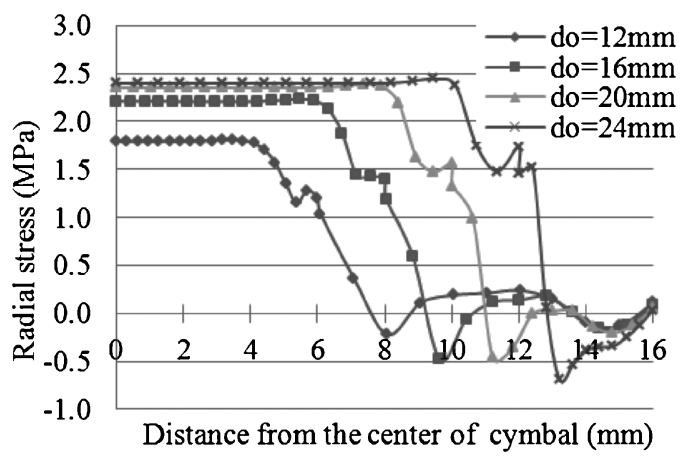

(b) Center of PZT

Fig. 11. Radial stress in PZT.

At the same time, enough area is needed to bond the PZT and end cap by the binder such as epoxy. The radial stress in PZT caused by the pressure applying on the top of the steel cap is shown as Fig. 11. The radial stress under the cavity in the PZT is almost uniform about $2 \mathrm{MPa}$. At the inner contact point of PZT and steel cap, there is a concentrate of stress. Out of that point the radial stress is very small. Assuming the radial stress in PZT under the cavity is driven by the bonder uniformly, and then the radial stress in the bonding layer should not larger than the peel strength of the bonder. The relation between peel strength and $d_{o}$ is shown in Fig. 12. The peel strength of epoxy bonder is between $0.3-1.2 \mathrm{MPa}^{16)}$ The curve in Fig. 12 shows that the radial stresses in bonding layer are all less than the peel strength $(0.3 \mathrm{MPa})$ for $d_{o} \leq 24 \mathrm{~mm}$. Considering the $U_{e}$, coupling effects with pavement and bonding, $d_{o}=22 \mathrm{~mm}$ is determined.

\subsection{Effects of $d_{i}$}

The FEA results of $U_{e}$ and $p_{d}$ vary in $d_{i}$ for $d_{c}=32 \mathrm{~mm}$, $h=2 \mathrm{~mm}, t_{p}=2 \mathrm{~mm}, t_{c}=0.3 \mathrm{~mm}$ and various $d_{o}$ are shown as

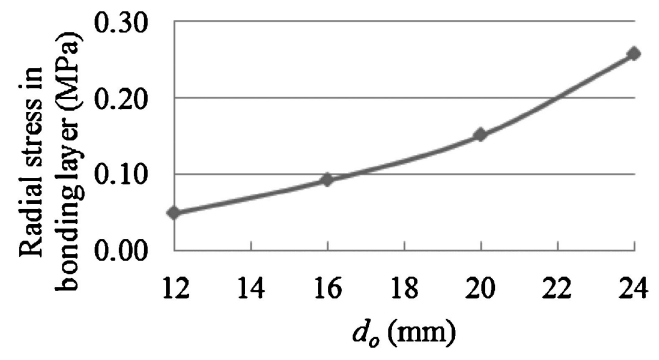

Fig. 12. $d_{o}$ vs. radial stress in bonding layer.

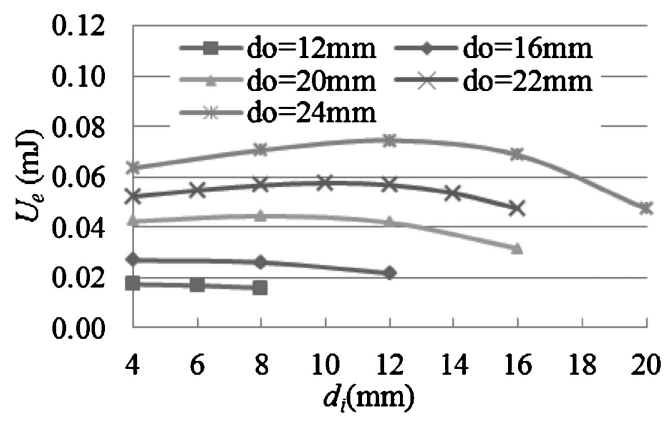

Fig. 13. $U_{e}$ vary in $d_{i}$.

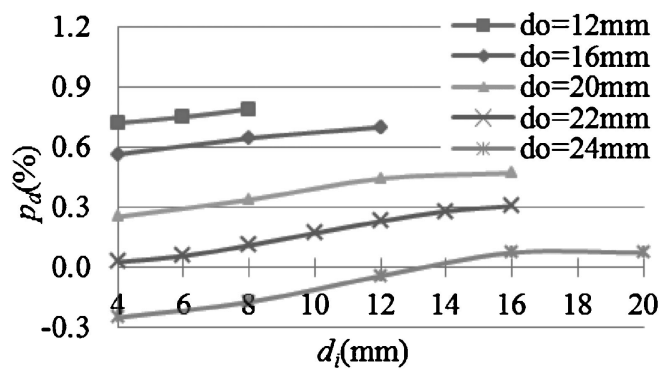

Fig. 14. Displacement difference with $d_{i}$.

Fig. 13 and Fig. 14. There is a maximum $U_{e}$ for various $d_{i}$ as shown in Fig. 13. The optimum $d_{i}$ at $d_{o}=22 \mathrm{~mm}$ is about $10 \mathrm{~mm}$. At the same time, the surface displacement of pavement has been reduced when $d_{i}=10 \mathrm{~mm}$ and $d_{o} \leq 22 \mathrm{~mm}$. Thus, $d_{i}=10 \mathrm{~mm}$ is suggested as the top diameter of Cymbal.

\subsection{Effects of $t_{c}$}

The thickness of end cap will also influence the performance of Cymbal. A Cymbals with $d_{c}=32 \mathrm{~mm}, d_{o}=22 \mathrm{~mm}$, $t_{p}=2 \mathrm{~mm}, d_{i}=10 \mathrm{~mm}$ and various $t_{c}$ and $h$ are analyzed through FEA. The FEA results are shown as Fig. 15 and Fig. 16. From Fig. 15, it can be concluded that there is a maximum $U_{e}$ at $t_{c}$ about $0.3 \mathrm{~mm}$ for various $h$. The $p_{d}$ increases with the increasing of $t_{c}$. For $t_{c}=0.3 \mathrm{~mm}$, the $p_{d}$ are larger than zero when $h$ is no less than $2 \mathrm{~mm}$. Thus, the $t_{c}=0.3 \mathrm{~mm}$ is suggested to build the Cymbal.

\subsection{Effects of $h$}

A Cymbals with $d_{c}=32 \mathrm{~mm}, d_{o}=22 \mathrm{~mm}, t_{p}=2 \mathrm{~mm}$, $t_{c}=0.3 \mathrm{~mm}$ and various $d_{i}$ and $h$ are analyzed for $h$ effects. The $U_{e}$ reach its maximum about $h=2-3 \mathrm{~mm}$ for all $d_{i}$ except $d_{i}=16 \mathrm{~mm}$ (see Fig. 17). The surface displacement of pavement decreases with the increasing of $h$ as shown in Fig. 18. Then, $h=2 \mathrm{~mm}$ is determined for $d_{i}=10 \mathrm{~mm}$ Cymbal. 


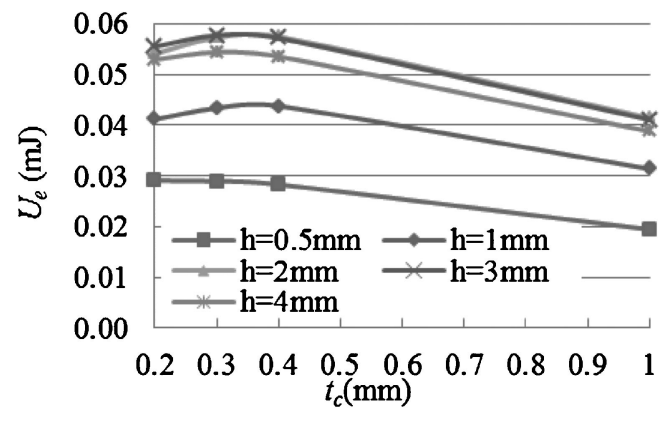

Fig. 15. $U_{e}$ vary in $t_{c}$.

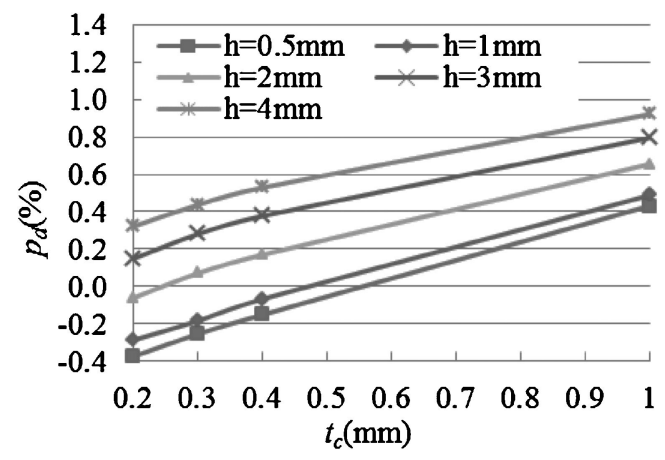

Fig. 16. Displacement difference with $t_{c}$.

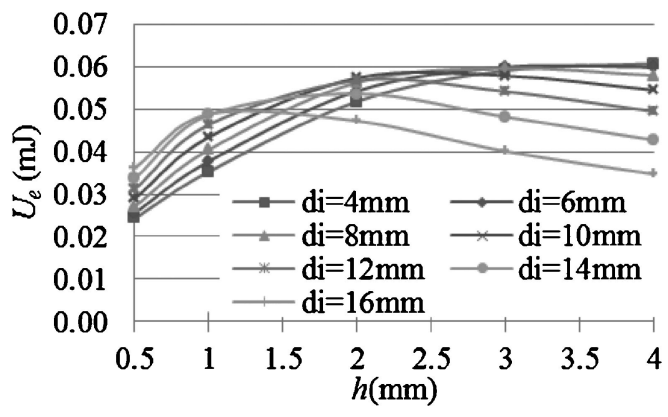

Fig. 17. $U_{e}$ vary in $h$.

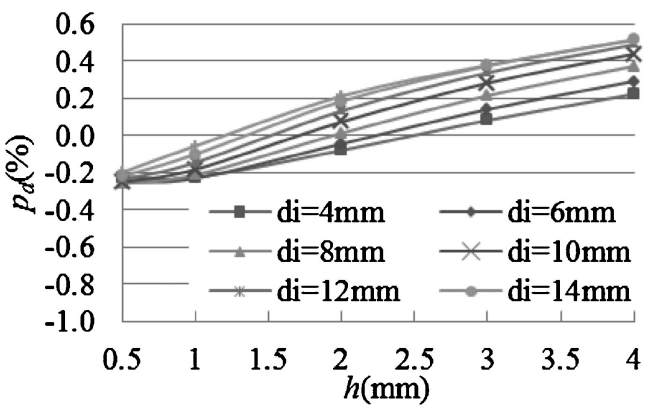

Fig. 18. Displacement difference with $h$.

\subsection{Effects of $t_{p}$}

The thickness of PZT is a key parameter influencing the performance of Cymbal. The Cymbals with $t_{p}=0.2,0.5,1.0$, $2.0,3.0 \mathrm{~mm}, t_{c}=0.3 \mathrm{~mm}, h=2 \mathrm{~mm}$ are evaluated via FEA (other sizes are listed in Table 2). The relation between $U_{e}$ and $t_{p}$ is shown in Fig. 19. $U_{e}$ increases with the thickness of PZT in the pavement environment. The increase rate becomes smaller when

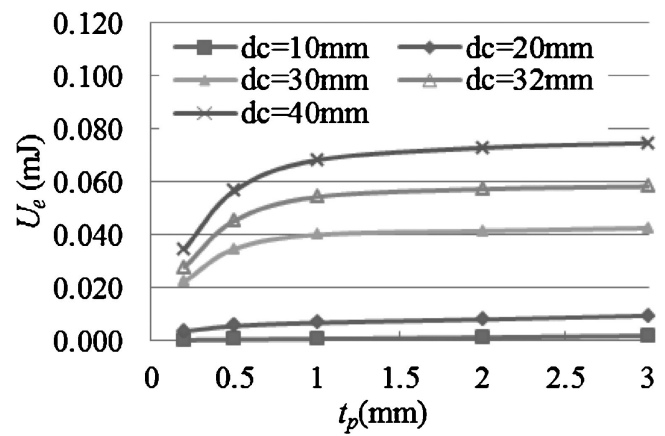

Fig. 19. $U_{e}$ vary in $t_{p}$.

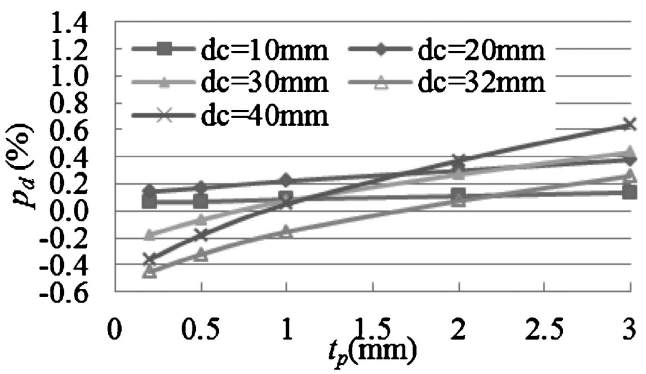

Fig. 20. Displacement difference with $t_{p}$.

$t_{p}$ is thicker than $1 \mathrm{~mm}$. The differences of displacement at the center point of pavement surface with and without Cymbal are shown in Fig. 20. The curve of $d_{c}=32 \mathrm{~mm}$ in Fig. 20 shows that the displacements with Cymbal are less than without Cymbal when the $t_{p}$ is larger than about $2 \mathrm{~mm}$. For those aspects, thicker PZT is better to build Cymbals. However, the cost increases with the PZT thickness. Combining those factors, $t_{p}=2 \mathrm{~mm}$ is suggested for Cymbal.

\section{Cymbal transducer design}

\subsection{Size}

Through the above FEA for $U_{e}$ and coupling effects with pavement, the optimum Cymbal size is determined. The Cymbal with $d_{c}=32 \mathrm{~mm}, d_{o}=22 \mathrm{~mm}, d_{i}=10 \mathrm{~mm}, t_{c}=0.3 \mathrm{~mm}, h=2$ $\mathrm{mm}$, and $t_{p}=2 \mathrm{~mm}$ is designed for harvesting energy from asphalt pavement.

\subsection{Performance}

Under the vehicle load, the designed Cymbal can generate a 97.33 V electric potential between the PZT surfaces based on the FEA model A. The potential maximum output electric energy is estimated about $0.06 \mathrm{~mJ}$ by Eq. (8). Assuming the frequency of the vehicle load is at $20 \mathrm{~Hz}$, then maximum $0.06 \times 20=1.2 \mathrm{~mW}$ electric energy will be harvested by each designed Cymbal from the asphalt pavement. The output power will be more if higher performance PZT material is used to build the Cymbal.

\section{Conclusions}

This paper discussed the performance of Cymbals for harvesting energy from the asphalt pavement. The potential electric energy $\left(U_{e}\right)$ generated by Cymbals are evaluated through FEA, which indicates the capability of a Cymbal transducer. At the same time, the surface displacements of pavement are analyzed to examine the coupling effects between Cymbals and the pavement. Based on the research presented in this paper, the following conclusions are made: 
(1) The displacement difference $p_{d} \geq 0$ is used to guarantee that the surface displacement of pavement with Cymbal is less than the displacement without Cymbal. Maximum electric energy $U_{e}$ and low cost are also used to choosing the size parameters.

(2) Two ABAQUS FEA models are compared under the contact load at $0.7 \mathrm{MPa}$. The model A, which the Cymbal is embedded directly in the asphalt pavement, is suggested to FEA because of its higher electric potential.

(3) $U_{e}$ increases with the diameter of Cymbal $\left(d_{c}\right)$. However, the cost also increases with $d_{c}$. There is a largest $p_{d}$ near $d_{c}=20 \mathrm{~mm}$. For cases with thin PZT, $p_{d}$ become negative between $d_{c}=20-30 \mathrm{~mm}$ except the thickness of PZT $t_{p}=2 \mathrm{~mm}$. Combing the energy harvesting capability, coupling effects with pavement and cost, $d_{c}=32 \mathrm{~mm}$ is suggested.

(4) $U_{e}$ increase with the diameter of the cavity base $\left(d_{o}\right)$. However, $p_{d}$ decreases with the increasing of $d_{o}$. For $t_{p}=2 \mathrm{~mm}$, $p_{d}$ becomes negative near $d_{o}=22 \mathrm{~mm}$. The bonding area is enough to bond the steel end cap and PZT when $d_{o}=22 \mathrm{~mm}$.

(5) There is a maximum $U_{e}$ when changing the top diameter of the end cap $\left(d_{i}\right)$. For $d_{c}=32 \mathrm{~mm}, d_{o}=22 \mathrm{~mm}$ and $t_{p}=2 \mathrm{~mm}$, the optimum $d_{i}$ is $10 \mathrm{~mm}$. At that point $p_{d}$ is larger than zero.

(6) $U_{e}$ reaches its largest value when the thickness of cap steel is near $0.3 \mathrm{~mm}$. There is also a maximum $U_{e}$ near $h=2 \mathrm{~mm}$.

(7) $U_{e}$ and cost increases with the thickness of PZT $\left(t_{p}\right)$. However, the increasing rate of $U_{e}$ decreases after $t_{p}>1 \mathrm{~mm}$. Thus $t_{p}=2 \mathrm{~mm}$ is chosen to build the Cymbal.

(8) Through a bunch of FEA, $d_{c}=32 \mathrm{~mm}, d_{o}=22 \mathrm{~mm}$, $d_{i}=10 \mathrm{~mm}, t_{c}=0.3 \mathrm{~mm}, h=2 \mathrm{~mm}$, and $t_{p}=2 \mathrm{~mm}$ is designed for Cymbal to harvest energy from asphalt pavement. Its $U_{e}$ is about $0.06 \mathrm{~mJ} .1 .2 \mathrm{~mW}$ maximum output power can be generated if the vehicle load is at $20 \mathrm{~Hz}$.

(9) Only single Cymbal is discussed in this paper based on FEA. The laboratory evaluating test needs to be done in the future. Cymbal arrays will be used in the field according the traffic and vehicle type. The performance of Cymbal array, such as efficiency, cost and coupling with pavement needs to be explored in the future as well. Following those works, how to storage electric energy and use them to light the traffic signal and light will be studied in the future.

Acknowledgements This work is completed at Pavement Research Center of UC Berkeley and UC Davis. The authors appreciated Professor John Harvey for providing the research requirement. This paper is supported by the Chinese National Natural Science Foundation Project: Research on Asphalt Pavement
Vibration under Moving Vehicle and the Coupling Effects with Piezoelectric Transducer (No. 50908177).

\section{References}

1) Ministry of Transportation of the People's Republic of China, http://www.moc.gov.cn/zhuzhan/tongjixinxi/fenxigongbao/ tongjigongbao/201004/t20100430_681272.html.

2) A. Dogan, J. F. Fernandez, K. Uchino and R. E. Newnham, Proceedings of the 10th IEEE International Symposium on Applications of Ferroelectrics, Aug. 18-21, East Brunswick, U.S.A, (1996) pp. 213-216.

3) A. Dogan, K. Uchino and R. E. Newnham, IEEE Trans. Ultrason. Ferroelectr. Freq. Control, 44, 597-605 (1997).

4) A. Dogan, J. F. Fernandez, K. Uchino and R. E. Newnham, IEEE J. Oceanic Eng., 32, 408-415 (2007).

5) J. F. Tressler, A. Dogan, J. F. Fernandez, J. T. Fielding, Jr., K. Uchino and R. E. Newnham, Proceedings of the 1995 IEEE Ultrasonics Symposium, Nov. 7-10, Seattle, U.S.A. (1995) pp. 897-900.

6) J. F. Tressler, W. Cao, K. Uchino and R. E. Newnham, IEEE Trans. Ultrason. Ferroelectr. Freq. Control, 45, 1363-1369 (1998).

7) R. E. Newnham, A. Dogan, D. C. Markley, J. F. Tressler, J. Zhang, E. Uzgur, R. J. Meyer, Jr., A. C. Hladky-Hennion and W. J. Hughes, Proceedings of the MTS/IEEE Oceans 2002 Conference and Exhibition, Oct. 29-31, Biloxi, U.S.A. (2002) pp. 2315-2321.

8) G. Wang, L. Wang, G. Li, G. Luan and F. Zang, Electron. Compon. Mater., 23, 33-35 (2004) [in Chinese].

9) C. Sun, S. Guo, W. Li, Z. Xing, G. Liu and X. Zhao, Sens. Actuators, A, 121, 213-220 (2005).

10) F. Tian, J. Cai, L. Lv and J. Qian, Torpedo Technol., 15, 51-54 (2007) [in Chinese].

11) H. W. Kim, A. Batra, S. Priya, K. Uchino, D. Markley, R. E. Newnham and H. F. Hofmann, Jpn. J. Appl. Phys., 43, 61786183 (2004).

12) H. W. Kim, S. Priya, K. Uchino and R. E. Newnham, J. Electroceram., 15, 27-34 (2005).

13) H. W. Kim, S. Priyal and K. Uchino, J. Appl. Phys., 45, 58365840 (2006).

14) D. Song and M. Xiao, "Piezoelectric effects and application," Popular science press, Beijing, China (1987).

15) A. A. Vives, "Piezoelectric transducers and applications second edition," Springer, New York, U.S.A. (2008).

16) A. Dogan, "Flextensional 'Moonie and cymbal' actuators." A thesis in materials program submitted in partial fulfillment of the requirements for the degree of Doctor of Philosophy (1994) pp. 63-66. 